\title{
Biogenêse mitocondrial e exercício físico: hipótese do acoplamento elétrico-transcripcional
}

CDD. 20.ed. 612.01421

796.027

http://dx.doi.org/10.1590/1807-55092015000400687
Benedito PEREIRA*

*Escola de Educação Física e Esporte,

Universidade de São Paulo.

\section{Resumo}

Uma das principais modificações ocorridas no organismo em decorrência do treinamento físico-esportivo envolvendo exercícios físicos de longa duração é o aumento na quantidade e qualidade funcional de mitocôndrias do tecido muscular esquelético. Não existe até o momento um mecanismo causal explicativo para esse fenômeno. A proposta a ser discutida neste ensaio é denominada por "hipótese do acoplamento elétrico-transcripcional". Segundo a mesma, modificações na atividade elétrica celular, principalmente de despolarização membranar, constituem-se em método de controle e regulação dos processos de biossintese no organismo multicelular. Por exemplo, estudos que provocaram hiperpolarização artificial em células somáticas induziram diferenciação celular e supressão da proliferação, sendo que o contrário ocorreu com a despolarização. Ou seja, a despolarização celular durante o exercício físico devido a contração muscular intensa e constante pode ativar processos responsáveis por biossínteses e, possivelmente, duplicação de mitocôndria.

Palavras-chave: Bioenergética; Bioeletricidade; Estresse oxidativo; Metabolismo; Resistência.

\section{Introdução}

Uma das principais modificaçóes ocorridas no organismo devido ao treinamento físico-esportivo (TFE) envolvendo a capacidade física de resistência é o aumento na quantidade e qualidade funcional de mitocôndrias do tecido muscular esquelético. Como mitocôndrias são responsáveis pela oxidação de intermediários bioenergéticos do catabolismo de glicose e ácidos graxos, utilizando $\mathrm{O}_{2}$ para tanto, essas modificaçóes ocorrem simultaneamente com o aumento na capilaridade e funcionalidade de sistemas de transporte desses substratos ${ }^{1}$. Neste ensaio, resistência diz respeito ao TFE com atividades físicas de longa duração, como no caso da preparaçẫo física do maratonista.

Biogênese mitocondrial envolve a expressão coordenada do genoma mitocondrial (mtDNA) e nuclear (nDNA) que produzem proteínas dessa organela. Entretanto, mitocôndrias não são ressintetizadas. No processo de sua replicação, novas proteínas são recrutadas e, posteriormente, adicionadas a compartimentos pré-existentes ou complexos de proteínas. Esse processo promove crescimento da organela em volume que sofre divisão subsequente por fissão ${ }^{2}$. Embora não exista um mecanismo explicativo para esse fenômeno, será sugerida neste ensaio a possibilidade de que modificaçóes na bioeletricidade celular pelo exercício físico possam contribuir significativamente para sua efetivação.

Em geral, quando ocorre despolarização do sarcolema pelo impulso nervoso ou de membranas de mitocôndrias devido às modificaçóes no fluxo de elétrons na membrana mitocondrial interna (MMI), com mudanças concomitantes em sua composiçáo iônica, o resultado corresponde à ativaçáo celular, enquanto o oposto ocorre com a hiperpolarização. Para os exemplos citados, a despolarização efetiva ocorre genuinamente apenas com células (neurônios) ou tecidos (tecido muscular) excitáveis ${ }^{3}$. Por exemplo, o valor do potencial de repouso do tecido muscular muda de -80 a $-90 \mathrm{mV}$ para aproximadamente $+30 \mathrm{mV}$ em decorrência da excitação nervosa.

Em células ou tecidos não-excitáveis, como no caso da MMI, a despolarizaçẫo não é efetivamente atingida. A MMI apenas se torna menos negativa, uma vez que mitocôndrias são as organelas mais negativamente carregadas das células. O resultado é a ocorrência de modificaçôes de cargas ao redor de membranas nestes tipos 
celulares. Isso ocorre porque todas as células possuem gradientes de voltagem em equilíbrio dinâmico ("steady state") que se mantém por longo tempo ao redor de suas membranas, como será explicado neste texto.

Portanto, o objetivo desse texto é o de discutir modificaçôes na bioeletricidade celular, principalmente da despolarização (queda no potencial de membrana

\section{Conceito de bioeletricidade}

Eletricidade biológica, ou bioeletricidade, é conduzida por íons inorgânicos, principalmente $\mathrm{H}^{+}, \mathrm{Na}^{+}$, $\mathrm{K}^{+}, \mathrm{Cl}^{-}$e $\mathrm{Ca}^{2+}$. Em células normais, gradientes de concentração desses íons fazem com que as mesmas apresentem potenciais de membrana bastante diversos ${ }^{4}$. Voltagem transmembranar é definida como o potencial elétrico extracelular menos o intracelular. Como o potencial extracelular é praticamente zero, a voltagem transmembranar é igual ao potencial intracelular, que é sempre negativo 5 . Uma vez que o transporte de íons entre os espaços intra - e extracelulares ocorre em muitos casos contra gradiente de concentraçáo, bioeletricidade pode ser um processo altamente consumidor de energia, como no caso da enzima $\mathrm{Na}^{+}-\mathrm{K}^{+}$-ATPase ${ }^{6}$.

$\mathrm{O}$ potencial de membrana celular é mantido ativamente em um valor relativamente constante. Este valor de voltagem é definido como potencial de repouso. Assim, nesta condição, células são quase sempre negativamente polarizadas. Por sua vez, o potencial de ação é um processo dinâmico que resulta da combinação de despolarização e repolarização, responsável por variaçôes nos valores da voltagem transmembranar. Por exemplo, com a ativação da fibra muscular por impulsos elétricos oriundos de motoneurônios, a membrana celular abandona seu estado polarizado, assumindo o estado despolarizado 7 . Esta condiçáo é seguida de retorno ao seu estado normal através de repolarização gradual.

Quando os elétrons fluem pelo sistema de transporte de elétrons mitocondrial (STE), um potencial de membrana muito negativo se estabelece. Por exemplo, o potencial de MMI ideal para a síntese de ATP situa-se entre -120 e $-140 \mathrm{mV}$. Portanto, qualquer ocorrência de distúrbios nestes valores, implicará em desfavorecimento da síntese de ATP8. Acima desses dois extremos, mudanças biofísicas complexas na MMI tornam a síntese de ATP inviável. Por exemplo, quanto maior o potencial de MMI, maior será a permeabilidade natural dessa membrana aos íons $\mathrm{H}^{+}$. Ou seja, menos $\mathrm{H}^{+}$torna-se disponível
- menos negativo) e hiperpolarização (aumento no potencial de membrana - mais negativo) de membranas plasmáticas e mitocondriais. Exemplos de seus efeitos sobre a capacidade de síntese de proteínas celulares serão discutidos, assim como a ocorrência de produção de fatores reguladores da transcrição de genes envolvidos nesse processo.

para gerar um gradiente com energia suficiente para a síntese de ATP. Por outro lado, o menor potencial de membrana é devido à queda na disponibilidade de elétrons transportados pelo STE'. Ou seja, o potencial redox celular (NADH e FADH) encontra-se abaixo do necessário para promover fluxo de $\mathrm{H}^{+}$na direção do espaço intermembranar ${ }^{10}$.

Em geral, gradientes de íons ao redor de membranas geram campos magnéticos e carga elétrica, assim como campo eletromagnético ultrabaixo, que são capazes de formar padrôes conformacionais em membranas celulares. Como nas células humanas, mitocôndrias encontram-se na forma tubular e associadas umas às outras, estendendo-se através do citosol e em contato íntimo com o núcleo celular, retículo endoplasmático, complexo de Golgi e citoesqueleto, esses campos magnéticos e corrente elétrica podem ser passados para vários componentes celulares, servindo como meio de comunicaçáo intracelular ${ }^{5}$. Portanto, no meio intracelular, mitocôndrias não se encontram como organelas independentes de outras estruturas e compartimentos celulares. $\mathrm{Na}$ verdade, formam uma rede reticular dinâmica, que passa continuamente por fusão e fissão ${ }^{11}$.

Para manter seus valores particulares quanto à bioeletricidade celular, há necessidade de coordenação de várias proteínas, em particular, bombas e canais de íons e outros tipos de transportadores (transportadores de açúcar e aminoácidos acoplados aos íons) $)^{5}$. Por exemplo, quando a musculatura se contrai, a fibra muscular despolariza devido à entrada de $\mathrm{Na}^{+}, \mathrm{Ca}^{2+}$ e ácidos orgânicos produzidos pelo metabolismo celular, concomitantemente à saída do $\mathrm{K}^{+}$da fibra muscular. O reverso ocorre com o relaxamento ${ }^{3}$. Todos os processos envolvidos com transporte de íons, neste caso, modificam as características elétricas da fibra muscular durante a movimentação resultante da contração muscular ${ }^{12}$.

Modificaçôes na bioeletricidade celular pelo exercício físico e TFE de resistência ainda não foram 
devidamente estudadas como possível fator envolvido com alterações de funçóes e estruturas celulares por essas formas de estimulação. Entretanto, ciclos prolongados de contração e relaxamento, como os ocorridos na corrida de longa duração, podem gerar modificaçóes no padrão de distribuição de cargas no meio intracelular. Ou seja, podem ocorrer ciclos concomitantes de despolarização e repolarização celular e de organelas nesta condição. O mesmo se aplica ao ciclo de consumo e produçáo de ATP por mitocôndrias durante esse evento. Dessa forma, a seguir serão discutidas diversas evidências favoráveis à ocorrência de modificaçóes na bioeletricidade celular como um possível fator responsável por biossínteses e biogênese de organelas em decorrência do TFE e exercício físico.

\section{Acoplamento elétrico-transcripcional}

Existem muitas evidências favoráveis à essa proposta. Por exemplo, estudos demonstraram que o potencial de repouso de membrana regula propriedades autônomas da célula como, proliferação, diferenciação e apoptose em células somáticas, células tronco e células cancerígenas ${ }^{3}$. Ou seja, a diferenciação e proliferação celular são também controladas por mudanças no valor do potencial de membrana, tanto plasmática como de organelas. Adicionalmente, a despolarização membranar sustentada é capaz de induzir síntese de DNA e mitose de neurônios. Além disso, células transferidas para cultura "in vitro" tendem a apresentar proliferação espontânea, que é precedida pela despolarizaçáo da membrana celular. Por outro lado, estudos que provocaram hiperpolarizaçáo artificial em células somáticas induziram diferenciação celular e supressão da proliferação. De fato, em células endoteliais humanas, a modulaçáo do potencial de membrana celular através da aplicação de campo elétrico revelou que a corrente hiperpolarizante promove redução na divisão celular ${ }^{13}$.

No começo da década de 70, Szent-Gyorgyi ${ }^{14}$ sugeriu que mudanças no movimento de cargas da célula podem alterar suas capacidades proliferativas: quando o potencial de membrana diminui, ocorre divisão celular e, eventualmente, aumento na sua quantidade $^{15}$. De acordo com Szent-Gyorgyi, para ocorrer replicação e biossíntese celular, o primeiro passo é a ocorrência de queda no fluxo de elétrons mitocondriais com falta concomitante de energia para manter a complicada estrutura e processos que sustentam a divisão celular e a mantêm sob controle. Com isso, a organização estrutural e funcional celular é perturbada a ponto de ativar significativamente a glicólise e via das pentoses. Através da ativação dessas vias metabólicas, componentes para a biossíntese são produzidos e utilizados na biogênese celular.

Despolarização é frequentemente considerada sinônimo de menor diferenciação celular e grande capacidade proliferativa e biossíntese. De fato, uma característica comum de células proliferativas (células tronco e embrionárias) e cancerígenas é o valor de potencial de membrana menor (entre -5 e $-30 \mathrm{mV}$ ) comparadas com células diferenciadas e saudáveis, como no caso de fibras musculares ${ }^{16}$. É interessante ressaltar que o potencial de membrana do fígado tem valor intermediário $(-38 \mathrm{mV})$ comparado com outros tecidos, como no caso do músculo esquelético. $\mathrm{O}$ valor intermediário de voltagem membranar de hepatócitos confere ao fígado grande plasticidade regenerativa ${ }^{3}$.

Devido à grande heterogeneidade no valor do potencial de repouso de membranas, há ocorrência de diferenças na sequência temporal de despolarização entre os diversos tecidos e células do organismo. Isso porque, quanto menos negativamente polarizada, mais efetivamente pode ser o processo de despolarização membranar pelo estímulo nervoso. No caso de mitocôndrias, mudanças no potencial de MMI não as tornam despolarizadas, mas menos negativamente polarizadas devido à ocorrência de queda na sua eficiência, alteraçóes negativas na oferta de poder redutor e outros processos a serem discutidos neste texto.

As diferenças apresentadas pelas fibras musculares I e II quanto aos seus potenciais de membrana e inervação por motoneurônios, fazem com que essas fibras sejam ativadas com frequências e tempos diferenciados. Outro fato importante é o tamanho do axônio do motoneurônio que inerva a fibra muscular (Princípio do Tamanho de Henneman ${ }^{17}$. Esse princípio determina que a ordem com que o neurônio motor seja ativado durante a contração muscular ocorra do menor para o maior ${ }^{18}$. Ressaltando que quanto maior o diâmetro da fibra nervosa, maior será a velocidade de conduçáo do impulso nervoso.

Por exemplo, se houver duplicação do raio do axônio, tanto o aumento da capacitância como a reduçáo da resistência da membrana, fatores que reduzem a velocidade de condução nervosa, serão por um fator 
de 2. Por outro lado, a redução da resistência interna (citoplasmática), o que aumentará a velocidade do impulso nervoso, ocorrerá por um fator de 4 . Como a redução da resistência supera o aumento da capacitância, o resultado é a elevação da velocidade da condução nervosa e, consequentemente, da força gerada pela contração muscular, por exemplo.

Estudos demonstraram que fibras musculares de contração rápida (tipo II), comparadas com fibras de contração lenta (tipo I), possuem potencial de membrana de repouso mais negativo. Além disso, tanto a amplitude do potencial de ação como a máxima velocidade de despolarização e repolarização, são maiores nas fibras de contração rápida ${ }^{19}$. Os valores de potencial de repouso de fibras musculares são: IIX $(-94,6 \mathrm{mV})$, IIA $(-92,7 \mathrm{mV})$ e tipo I $(-85,3 \mathrm{mV})^{12}$.

A capacitância de membrana por unidade de área é similar em fibras de contração lenta e rápida. Valores respectivos de 3,82 "versus" $3,76 \mu \mathrm{F} / \mathrm{cm}^{2}$ têm sido obtidos para essas fibras em músculos de humanos. Por outro lado, a resistência elétrica da membrana por unidade de área é maior em fibras de contração lenta comparadas com fibras rápidas $\left(588 \Omega / \mathrm{cm}^{2}\right.$ nas primeiras e $358 \Omega / \mathrm{cm}^{2}$ nas segundas). As unidades motoras que são lentamente ativadas são aquelas que mais suportam a intensidade do esforço físico (tipo I), sendo recrutadas durante todo tipo de contração muscular. Por outro lado, as do tipo II entram em fadiga rapidamente e são recrutadas com baixa frequência ${ }^{20}$.

Com relação ao músculo esquelético, assim que o potencial de ação do motoneurônio se dirige para o interior da fibra, a membrana do túbulo T é despolarizada e repolarizada, gerando um circuito de ativação repetitiva. Esse processo é desencadeado pela acetilcolina liberada na fenda sináptica entre o neurônio e a superfície da fibra. Fibras musculares possuem condutância elevada para o $\mathrm{Cl}^{-}$, que faz com que a membrana muscular fique mais difícil de estimular comparativamente à célula nervosa. Isso é importante porque reduz as chances de ativação repetitiva ${ }^{12}$. Como consequência, o músculo é despolarizado e relaxado mais facilmente.

Esse efeito é creditado à sua grande quantidade de transportadores de $\mathrm{Cl}^{-21}$. A expressão desses transportadores (denominado por ClC-1) é maior em fibras de contração rápida, comparado às de contração lenta, sendo altamente modulada por atividade elétrica. Portanto, embora fibras de contração rápida possuam menor resistência membranar que as de contração lenta, sua repolarização é mais efetiva comparadas com fibras do tipo I. Um exemplo interessante sobre a importância desse mecanismo é a condição clínica "miotomia congênita", na qual a condutância para o $\mathrm{Cl}^{-}$do tecido muscular é reduzida, com consequente ativação repetitiva (queda no relaxamento muscular). Ou seja, o músculo perde a funcionalidade do canal de $\mathrm{Cl}^{-}$, sendo incapacitado de repolarizar e, consequentemente, de relaxar a musculatura esquelética ${ }^{21}$.

Essas propriedades elétricas de fibras musculares podem explicar as diferenças existentes entre suas capacidades relacionadas com biossíntese e duplicação de organelas. Por exemplo, pesquisas demonstraram que: 1) Fibras musculares do tipo I encontram-se mais susceptíveis a manterem o estado de despolarização membranar por mais tempo, comparadas com as do tipo II; 2) Fibras de contração lenta possuem ao mesmo tempo alta capacidade oxidativa e capacidade de síntese proteica, comparadas com fibras de contração rápida ou aquelas menos oxidativas; 3) Existe competição por sinais relacionados com síntese de proteínas miofibrilares e proteínas associadas com metabolismo oxidativo. Ou seja, o aumento na biogênese mitocondrial atenua a velocidade de síntese de proteínas estruturais e duplicação de outras organelas e; 4) Existe grande expressão de proteases envolvidas com degradação proteica em fibras musculares altamente oxidativas.

Essas observaçóes adicionais podem explicar o paradoxo envolvendo fibras de contração lenta e grandemente oxidativas que, apesar de possuírem alta capacidade para a síntese de proteínas, essas fibras permanecem pequenas comparadas com as de contração rápida. Ou seja, existe relação inversa entre o tamanho e as capacidades oxidativas de fibras musculares ${ }^{22}$.

Considere, por exemplo, a velocidade da condução nervosa de um neurônio ou do tecido muscular, que depende da densidade de canais de $\mathrm{Na}^{+}$: quanto maior a sua densidade, maior será a corrente iônica e a velocidade da condução do impulso nervoso. Contudo, essa relação é válida somente dentro de alguns limites, porque esses canais e suas comportas também contribuem para a elevação da capacitância celular. Portanto, existe um limite em que a adição membranar de mais canais de $\mathrm{Na}^{+}$é contraproducente ${ }^{23}$.

Isso significa que devem existir "feedbacks" entre as propriedades elétricas do nervo e o nível de expressão dessas proteínas, que é conhecido como "acoplamento elétrico-transcripcional" ${ }^{24}$. Portanto, existem relaçóes entre níveis elevados da funcionalidade celular e os níveis mais elementares representados pelos seus constituintes. Neste caso, entre o potencial elétrico celular e a cinética do canal. Como esses canais possuem propriedades oscilatórias, se o "feedback" for removido, essa propriedade deixa de existir, demonstrando ser uma propriedade do 
sistema, não de um canal individual ou mesmo de um conjunto deles.

Neste caso em particular, pode-se fazer, como consequência dessas observaçóes, a seguinte indagação: o que vem primeiro, as propriedades cinéticas do canal ou o potencial elétrico célular? Experimentos realizados em laboratório revelaram que na falta de componentes estruturais celulares e fatores presentes na célula não ocorre geração do ritmo cardíaco ${ }^{24}$. Portanto, pode-se dizer que as proteínas que formam canais iônicos em células excitáveis geram corrente elétrica que respondem pela sua capacitância, sendo isso um tipo de controle a partir dos componentes sistêmicos. Mas, o potencial elétrico da célula também controla a comporta do canal. $\mathrm{Ou}$ seja, os componentes alteram o comportamento do coração, e este, por sua vez, altera o comportamento dos seus componentes.

Fatores que alteram a eficiência bioenergética também interferem no comportamento da bioeletricidade celular e biossíntese. Por exemplo, estudos alométricos com animais e humanos mostraram que organismos maiores são mais eficientes e possuem menos mitocôndrias por grama de tecido muscular, comparados com animais menores (peso e altura) ${ }^{25}$. Foi também observado que é mais comum serem encontrados na natureza indivíduos maiores mais envolvidos com atividades físicas em que a força e a potência anaeróbia predominam; enquanto animais menores, com atividades físicas de longa duração ${ }^{26}$. Isso ocorre, provavelmente, devido à diminuição da superfície corporal com o maior tamanho. Com isso, o indivíduo maior passa a apresentar dificuldades termorregulatórias ${ }^{27}$.

Portanto, pode-se dizer que a alta demanda bioenergética e seu desperdício são possíveis fatores responsáveis pela proliferação mitocondrial no tecido de animais menores, comparados com animais de grande porte físico. Ou seja, despolarização de membrana devido à queda na eficiência bioenergética com o menor tamanho corporal pode ser o fator responsável pela sinalização que desencadeia biossínteses e biogênese mitocondrial. Em favor dessa afirmação, foi demonstrado que animais menores apresentaram expressão tecidual elevada de reguladores da transcrição gênica (PGC-1 $\alpha$ ["peroxisome proliferator-activated (PPAR)- $\gamma$ coactivator- 1 ”], CaMK $\left[\mathrm{Ca}^{2+}\right.$-calmodulina quinase] e AMPK [adenosina monofosfato quinase]) envolvidos com proliferação mitocondrial, comparados com animais maiores ${ }^{28}$.

Portanto, ciclos de desperdícios bioenergéticos com despolarização de MMI e ativação da glicólise e via das pentoses são pré-requisitos para a duplicação de mitocôndrias e biossínteses no tecido muscular. Por outro lado, o aumento no número de mitocôndrias teciduais eleva a eficiência bioenergética oxidativa do organismo e estabiliza o potencial elétrico de MMI em valores próximos de 3,6 ${ }^{29}$. Ressaltando que os estados redox mitocondriais oscilam entre os valores de 3 (alta demanda por ATP) e 4 (repouso). No estado 3, a MMI encontra-se despolarizada, comparativamente ao estado 4. Esses dados foram obtidos através de experimentos envolvendo mensuraçóes de consumo de $\mathrm{O}_{2}$ em meio a alteraçóes na oferta de poder redutor para mitocôndrias "in vitro"29.

Quanto ao papel da glicólise na biossíntese e proliferaçáo celular, sua importância, neste caso, foi primeiramente descrita por Otto Warburg ${ }^{30}$, quando demonstrou que células tumorais e tecidos proliferativos possuem grande atividade glicolítica, consumindo grandes quantidades de glicose com consequente produção acelerada de lactato. A via das pentoses também se encontra bastante ativa nestes tipos celulares, comprovado pela alta atividade de glicose-6-fosfato desidrogenase ${ }^{31}$. Estudos sobre reprogramação celular demonstraram que células terminais são predominantemente oxidativas, enquanto que células indiferenciadas e proliferativas, glicolíticas ${ }^{31}$.

Outros dados que atestam a importância da glicólise e via das pentoses para a biossíntese e proliferação de mitocôndrias foram obtidos com estudos envolvendo proteínas UCPs ("uncoupler proteins”) e DNF (dinitrofenol). Proteínas UCPs e DNF são desacopladores da fosforilação oxidativa ${ }^{32}$. Ou seja, são causadores de desperdício bioenergético por mitocôndrias e ativam de maneira exacerbada a via glicolítica. Foi demonstrado que pequenas doses de DNF por seis meses promovem aumento na longevidade de camundongos e elevação no teor mitocondrial do músculo esquelético ${ }^{33}$.

Como o desacoplamento mitocondrial por DNF e proteínas UCPs promove vazamento de íons $\mathrm{H}^{+} \mathrm{da}$ MMI, reduzindo o potencial redox celular necessário para a síntese de ATP pela fosforilação oxidativa, o mecanismo possivelmente envolvido com aumento na quantidade de mitocôndrias por esses desacopladores pode envolver modificaçóes nas características bioelétricas de $\mathrm{MMI}^{32}$. Neste estudo, em resposta ao desacoplamento mitocondrial, mRNA de vários fatores de transcrição foram claramente aumentados, a saber: PGC-1 $\alpha$, PGC-1 $\beta$, NRF1 ("nuclear respiratory factor 1") e 2-TFAM ("mitochondrial transcription factor 2 "). 
Outros experimentos demonstraram que o aumento moderado na expressão (2-3 vezes) da isoforma 3 da UCP (UCP3) no músculo esquelético de camundongos foi capaz de mimetizar os efeitos induzidos normalmente pelo TFE de resistência. Por exemplo, a atividade espontânea dos animais aumentou em 40\% e a liberação de energia em 5-20\%, com redução no estresse oxidativo (15-20\%) $)^{34}$. Obteve-se, também, aumento em $30 \%$ na oxidação de ácidos graxos, além de outros efeitos constatados.

Esses efeitos induzidos pelo desacoplamento mitocondrial ressaltam a importância da bioenergética celular e da preservaçáo de seus componentes, como no caso do potencial de MMI e do ambiente redox celular, que é crucial para diversas funções como divisão, diferenciação e trabalho muscular, por exemplo ${ }^{35}$. Estresse oxidativo significa maior produção de espécies reativas de $\mathrm{O}_{2}$ (EROs) comparado com defesas antioxidantes químicas e enzimáticas disponíveis. As principais EROs produzidas no interior de mitocôndrias que serão comentadas neste texto são: ânion radical superóxido $\left(\mathrm{O}_{2}^{-}\right)$, peróxido de hidrogênio $\left(\mathrm{H}_{2} \mathrm{O}_{2}\right)$ e radical hidroxil $\left({ }^{\circ} \mathrm{OH}\right)$.

Portanto, é possível que a despolarização de membranas ou seu estado menos polarizado sejam pré-requisitos para desencadear a síntese ou duplicaçáo de componentes celulares ${ }^{6}$. Ou seja, para que células proliferem e propiciem regeneração, há necessidade que regridam para estágios mais imaturos da diferenciação celular. O principal fator relacionado com esse evento é a despolarização de cargas, que culmina em queda na capacidade mitocondrial de produção de ATP, passando a obter mais energia do catabolismo não-oxidativo de substratos ${ }^{14}$. Uma informação importante sobre esse tema é a de que células tronco "in vivo” se localizam em regióes hipóxicas do organismo.

\section{Desacoplamento mitocondrial e bioenergética}

Mitocôndrias são imprescindíveis para as células porque produzem grandes quantidades de ATP por processos oxidativos. Para tanto, equivalentes de elétrons sáo obtidos de NADH e FADH produzidos, principalmente, pelo ciclo de Krebs e $\beta$-oxidação. Esses elétrons fluem através do STE constituído por complexos proteicos, cuja função é propiciar o bombeamento de $\mathrm{H}^{+}$por canais específicos presentes em três componentes desse sistema ${ }^{9}$. No final do $\mathrm{STE}$, o $\mathrm{O}_{2}$ é reduzido a água. Como consequência do fluxo de elétrons pelo STE, íons $\mathrm{H}^{+}$passam a se acumular em grande quantidade no espaço entre MMI e a membrana mitocondrial externa (MME), resultando em elevado gradiente de $\mathrm{H}^{+}$entre esse espaço e a matriz mitocondrial.

Devido as mitocôndrias serem grandemente negativas, $\mathrm{H}^{+}$localizados no espaço intermembranar passam a se deslocar efetivamente para a matriz mitocondrial através da enzima ATP sintase $\left(\mathrm{F}_{1} \mathrm{~F}_{0}\right.$ ATP sintase). Durante o transporte de $\mathrm{H}^{+}$a energia do gradiente é utilizada por essa proteína para sintetizar ATP. O ADP utilizado para tanto é oriundo do citoplasma celular, com participação do sistema de translocase de adenina (ANT) ${ }^{8}$.

O sistema ANT catalisa reação eletrogênica, porque uma carga negativa é expelida da matriz mitocondrial para o citosol durante cada ciclo de transporte de $\mathrm{ATP}^{4-}$ para fora da mitocôndria e de $\mathrm{ADP}^{3-}$ para dentro. Em função do alto potencial negativo de MMI, essa condiçáo favorece a condução do ATP para o citoplasma e captação de ADP por mitocôndrias. Assim, pode-se dizer que o alto valor negativo da MMI direciona a liberaçáo do ATP para o citosol e o ADP para a matriz mitocondrial, fazendo com que a razáo ATP/ADP e o valor de energia útil sejam maiores no citosol ${ }^{36}$.

$\mathrm{Na}$ verdade, a razão ATP/ADP é 50 a 100 vezes maior no citosol comparada com a matriz mitocondrial em células com metabolismo oxidativo ativo como, neurônios, cardiomiócitos, hepatócitos e fibras musculares. A energia contida no gradiente de $\mathrm{H}^{+}$no espaço intermembranar devido à passagem de elétrons pelo STE não é importante somente para sustentar a síntese de ATP, sendo também crucial para outras funçōes mitocondriais como, fusão de mitocôndrias, importação de proteínas, trocas de metabólitos com o citosol e indução de apoptose. Neste sentido, o potencial de MMI pode ser considerado um importante indicador de qualidade funcional de mitocôndrias ${ }^{34}$.

A atividade respiratória mitocondrial interfere nos valores do potencial elétrico de MMI e pode ser alterada utilizando-se diferentes estratégias, incluindo, maior disponibilidade de substratos, estresse oxidativo, desacoplamento mitocondrial e restrição calórica. Por exemplo, o consumo de doses elevadas de substâncias com grande poder redutor produz efeitos ergogênicos por aumentar o movimento de 
elétrons nas mitocôndrias ${ }^{6}$. Outra estratégia é promover desacoplamento mitocondrial, resultando em respiração aumentada sem fosforilação. Além dos exemplos já citados (UCPs e DNF), ácidos graxos são desacopladores efetivos da fosforilaçáo oxidativa ${ }^{37}$.

Restrição calórica prolongada resulta em queda no potencial de membrana devido a menor oferta de $\mathrm{NADH}$ e FADH ou, em funçáo do aumento no vazamento de $\mathrm{H}^{+}$através da MMI, com consequente redução na produção de $\mathrm{EROs}^{38}$. Proteínas da MMI, como as UCPs e ANTs, podem facilitar o vazamento de $\mathrm{H}^{+}$na direção da matriz mitocondrial, resultando em desacoplamento da MMI. Outro fator que contribui nesse processo é a composição de fosfolipídeos da MMI. Ou seja, quanto mais rica em ácidos graxos polinsaturados, maior a possibilidade de desacoplamento mitocondrial'.

No caso do exercício físico, cogita-se sobre a possibilidade de aumento no aproveitamento da energia do gradiente de $\mathrm{H}^{+}$mitocondrial para a formação de ATP, devido ao aumento na quantidade de mitocôndrias do tecido muscular esquelético pelo TFE de resistência. O exercício físico intenso e prolongado é uma forma de estresse que promove queda na eficiência da fosforilação oxidativa, com redução concomitante na capacidade bioenergética celular e produção mitocondrial de $\mathrm{EROs}^{39}$. Portanto, o aumento na quantidade de mitocôndrias do tecido muscular pelo TFE poderia amenizar esse efeito do exercício físico intenso ${ }^{40}$.

Com mais mitocôndrias por grama de tecido, cada STE passa a apresentar atividade reduzida no repouso ou em menor intensidade durante o exercício físico prolongado ${ }^{40}$. No repouso, a maior eficiência mitocondrial eleva a pressão de elétrons no STE e favorece a hiperpolarização da MMI, com possibilidades de maior formação de EROs nesta condição, principalmente se houver grande consumo de nutrientes com alto poder redutor em meio à baixa demanda por $\mathrm{ATP}^{29}$. Para proteger as células do estresse oxidativo, a hiperpolarização ativa o desacoplamento mitocondrial. Ou seja, existem mecanismos intramitocondriais que reduzem as possibilidades de produção excessiva de EROs, nesta condição $^{32}$. O mecanismo responsável por esse efeito pode ser a maior ativaçáo de proteínas UCPs pela hiperpolarização da MMI.

\section{Metabolismo celular e bioeletricidade}

Estímulos que impóem progressivamente alta demanda bioenergética ao organismo resultam em resposta celular bifásica (não-linear). Por exemplo, estímulos com baixa intensidade (Fase I) promovem queda na turbidez e viscosidade do citoplasma, com a possibilidade de hiperpolarização da membrana e consequente resistência ao agente estressor. Por outro lado, estímulos intensos (Fase II) elevam a turbidez, viscosidade, promovem despolarização de membrana e queda na resistência à sobrecarga do estímulo ${ }^{41}$.

Quando o estímulo do exercício físico na Fase II se estende por muito tempo, mecanismos de sinalização, controle e regulação do metabolismo celular são ativados. Dentre esses, os que serão discutidos neste texto são a AMPK, que é sensível às mudanças nos valores celulares de ATP e, enzimas sirtuínas ("Sirtuins"), que detectam valores modificados de $\mathrm{NAD}^{+} / \mathrm{NADH}^{42}$.

Existem muitas evidências de que tanto a ativação muscular intensa por estimulação elétrica ou em condiçóes de locomoção natural de animais e humanos, há ativação da $\mathrm{AMPK}^{43}$. A AMPK ativada exerce função estimulatória de genes envolvidos com o transporte celular de glicose (GLUT-4) e sua utilização, assim como a oxidação lipídica. Esses processos ocorrem devido ao efeito desta enzima sobre efetores transcripcionais, principalmente PGC- $1 \alpha$. Na verdade, PGC-1 $\alpha$ é considerado um regulador central da expressão gênica mitocondrial, estando envolvido no controle e coordenação de transcritos mitocondriais e nucleares ${ }^{44}$.

O PGC-1 $\alpha$ é um importante condutor de informaçóes para sítios de controle da expressão gênica nuclear responsivos ao estresse típico do TFE de resistência. O PGC-1 $\alpha$ é regulado por fosforilação e acetilação pós-traducional, sendo que sua acetilação reversível modifica significativamente sua atividade transcripcional, com participação de SIRT1; uma enzima desacetilase dependente de $\mathrm{NAD}^{+42}$. O mecanismo da fosforilaçáo de PGC-1 $\alpha$ envolve a enzima AMPK.

$\mathrm{Na}$ verdade, sirtuínas são sensores de energia celular que necessita de $\mathrm{NAD}^{+}$para sua atividade enzimática. Assim, com o aumento na razão de $\mathrm{NAD}^{+} / \mathrm{NADH}$, valores de nicotinamida aumentam e ativam sirtuínas. Portanto, qualquer situação que imponha déficit de energia ou intensa atividade catabólica de substratos bioenergéticos pode resultar em aumento no $\mathrm{NAD}^{+}$que ativará sirtuínas, como no caso do exercício físico intenso. Sirtuínas removem 
grupos acetila de resíduos de lisinas acetiladas de um grande número de proteínas alvos, incluindo histonas e fatores de transcrição ${ }^{42}$. Portanto, o estado celular oxidado e, consequentemente, mais despolarizado, é um importante fator para a ativação de enzimas sirtuínas e AMPKs.

Como consequência do jejum e do exercício físico prolongado, o músculo esquelético passa a consumir progressivamente mais lipídeos, reduzindo a velocidade de consumo de carboidratos. Essa mudança na "preferência” muscular por lipídeos, nestes casos, é resultado da ativação de mecanismos intracelulares ativadores da $\beta$-oxidação e controladores da transcrição que resultam nesta mudança. Nesta condição de exercício físico intenso prolongado, em associação ao maior consumo de ácidos graxos, mitocôndrias tornam-se menos eficientes e mais despolarizadas, comparativamente ao consumo de glicose. Quando isso ocorre, a AMPK atua como sensor inicial que traduz a presença de indicadores de deficiência bioenergética em informaçóes que culminam na desacetilação de PGC-1 $\alpha$ pela SIRT1. A deficiência de AMPK compromete esse processo, o que permite concluir sobre a atuação da AMPK como desencadeadora primordial para as modificaçóes metabólicas decorrentes do jejum e exercício físico prolongado ${ }^{45}$.

Em paralelo, vários polifenóis possuem a propriedade de ativar SIRT1 "in vitro", com a possibilidade de induzir biogênese mitocondrial "in vivo" através da desacetilação de PGC-1 $\alpha$. Resveratrol (presente em uvas e vinho tinto) é efetivo em ativar SIRT1 e induzir desacetilação de PGC-1 $\alpha$, com ativação da sua atividade transcripcional no fígado e músculo esquelético de camundongos. Além da SIRT1, a AMPK é fundamental para os efeitos metabólicos exercidos no organismo pelo resveratrol. Estudos que bloquearam os efeitos da SIRT1 e da AMPK foram capazes de prevenir a biogênese mitocondrial "in vivo". Em mamíferos existem sete enzimas "sirtuínas" (SIRT1-7). Dentre essas, a do tipo 1 foi a mais estudada. Foi descrito que a SIRT3 se encontra preferencialmente no interior de mitocôndrias.

Diversos substratos foram identificados para enzimas SIRT, sendo que vários destes são reguladores da fosforilação oxidativa, metabolismo lipídico e do processo de envelhecimento ${ }^{46}$. Esses efeitos são também constatados para a quercitina (presente em maçãs, brócolis, cebolas, etc.) e hidroxitirosol (presente em azeitonas e no óleo de oliva extra virgem $)^{47}$. Alguns polifenóis são também capazes de induzir desacoplamento mitocondrial e estimular a biogênese mitocondrial por esse mecanismo, como proposto neste ensaio ${ }^{47}$.
Para o exercício físico exercer efeito significativo para despolarizar membranas celulares e induzir alteraçôes consistentes sobre a expressão gênica, estímulos semelhantes aos de Fase II são necessários. O porquê de estímulos moderados por longo tempo, como os de Fase I, tornarem as membranas celulares progressivamente mais resistentes à despolarização pode estar relacionado com a maior oferta de poder redutor pelo STE em meio a uma baixa demanda por ATP e $\mathrm{O}_{2}$, assim como com mudanças ocorridas em propriedades eletrofisiológicas do sarcolema e de motoneurônios. No primeiro caso, a MMI tende a se hiperpolarizar, enquanto no segundo, o resultado é redução progressiva na descarga de unidades motoras em humanos ${ }^{48}$.

Por exemplo, um treinamento de 16 semanas com exercícios de longa duração com animais (ratos) resultou em hiperpolarização do potencial de repouso de motoneurônios, aumento no seu limiar de excitabilidade e de outros parâmetros envolvendo o impulso nervoso ${ }^{49}$. Além disso, durante a ativação neuronal repetitiva, a junção neuromuscular de fibras de contração rápida e lenta exibiram depressão sináptica significativa, que foi maior nas segundas. Esse efeito pode estar relacionado com redução no número de vesículas com neurotransmissor liberadas pelo estímulo na fenda sináptica e na quantidade desse neurotransmissor (acetilcolina) ${ }^{12}$.

Outro mecanismo envolvido com esses problemas relaciona-se com modificaçóes nas concentraçóes citosólicas de $\mathrm{Ca}^{2+}$. Por exemplo, no repouso sua concentração é maior em fibras de contração lenta comparadas com as de contração rápida, o que contribui significativamente para o menor potencial de repouso nas primeiras, comparativamente às segundas, como previamente descrito. No repouso, a influência da concentração de $\mathrm{Ca}^{2+}$ na determinação e manutenção do fenótipo da fibra muscular foi proposta por alguns autores e comprovada em experimentos com miotubos de músculos de coelho em cultura. Os experimentos assim realizados demonstraram que a indução de aumento no $\mathrm{Ca}^{2+}$ nessas células por ionóforos específicos é seguido de transformação da fibra rápida em lenta ${ }^{12}$.

Em termos funcionais, uma mudança descrita envolvendo o efeito do exercício físico ou da estimulação elétrica do tecido muscular é a queda na potenciação de sinapse devida ao aumento da concentração intracelular de $\mathrm{Ca}^{2+}$ mantida constante por longo tempo ${ }^{50}$. A hipótese central envolvendo o papel do $\mathrm{Ca}^{2+}$ quanto a esse efeito é a de que seu aumento no meio intracelular em grandes 
quantidades promove o fenômeno da potenciação de sinapse, enquanto que seu aumento moderado e por longo tempo, o oposto (depressão) ${ }^{50}$. Portanto, em longo prazo, a queda nos efeitos do $\mathrm{Ca}^{2+}$ na ativação de sinapses de células excitáveis dificulta a despolarização celular pelo impulso nervoso.

A depressão nos efeitos sinápticos do impulso nervoso na fibra de contração lenta, assim como a maior biossíntese voltada para a duplicação de mitocôndrias, podem diminuir a disponibilidade de energia para a síntese de miofibrilas e contribuir para que sejam menores, comparadas com as do tipo II, como descrito antes. Quanto a isso, outro fator possivelmente envolvido diz respeito às modificaçóes negativas ocorridas na eficiência bioenergética com a duração do esforço físico ${ }^{51}$. De fato, as leis termodinâmicas consideram que a eficiência diminui progressivamente com o aumento no tempo das transformaçóes energéticas em sistemas complexos. Além disso, existe relação inversa entre oferta de energia e duração da demanda?

Por outro lado, embora a contração muscular sustentada não possa ser realizada com grande intensidade devido ao fenômeno da depressão sináptica, como previamente descrito, a manutenção dos valores intracelulares de $\mathrm{Ca}^{2+}$ sob controle e em baixos valores é fundamental para a funcionalidade e proteção celular contra a estimulação de eventos relacionados com apoptose e injuria celular, como será explicado adiante ${ }^{18}$. Neste caso, a captação de $\mathrm{Ca}^{2+}$ por mitocôndrias é o fator mais importante no desencadeamento desses efeitos. Ressaltando que a deficiência bioenergética durante o exercício físico intenso prejudica o transporte de $\mathrm{Ca}^{2+}$ de volta aos seus locais de armazenagem ${ }^{12}$.

\section{Produção de EROs e bioeletricidade}

A velocidade mitocondrial de produção de EROs depende da energia do gradiente de $\mathrm{H}^{+}$no espaço intermembranar, razão $\mathrm{NAD}^{+} / \mathrm{NADH}$, estado redox de coenzima Q10 ( $\mathrm{CoQH}_{2} /$ coenzima Q10 [CoQ]) e concentração local de $\mathrm{O}_{2}$. Nas condiçóes de alto potencial redox mitocondrial, alta razáo $\mathrm{CoQH}_{2} / \mathrm{CoQ}$ ou maior disponibilidade de $\mathrm{NADH}$, a produção mitocondrial de EROs é favorecida ${ }^{52}$. Como há grande oferta de elétrons para o STE nesta condição, em associaçáo à pequena demanda por ATP, a MMI tende a ficar hiperpolarizada; o contrário ocorrendo quando há alta demanda por ATP. Portanto, a ocorrência de despolarização de MMI pode retratar uma modificação fisiológica envolvida com aumento na demanda celular por ATP ${ }^{8}$.

De fato, quanto menor o potencial de MMI, menor será a produção intramitocondrial de $\mathrm{EROs}^{53}$. Neste caso, duas condiçóes favorecem a despolarização de MMI: 1) Durante a fosforilação oxidativa devido ao aumento de $\mathrm{H}^{+}$na matriz mitocondrial e; 2) Quando a demanda por energia se encontra elevada. Portanto, o exercício físico pode promover redução no potencial de MMI e menor produção de EROs. Outro efeito do exercício físico ainda a ser comentado e que contribui para a despolarização de mitocôndrias é a sua captação de $\mathrm{Ca}^{2+}$.

A menor oferta de poder redutor para o STE mitocondrial também promove esse efeito. Isso ocorre como consequência, por exemplo, da dieta com restrição calórica. Porém, quando se torna hiperpolarizada, há maior possibilidade de formação de EROs devido ao aumento na oferta de elétrons para o STE. Lembrando que, como afirmado antes, mitocôndrias podem ativar mecanismos de desperdício bioenergético que minimizam esses efeitos ${ }^{29}$.

Em favor da hiperpolarização como mecanismo envolvido com aumento na produção intracelular de EROs, sabe-se que a hipóxia pode reduzir a velocidade de transporte de elétron mitocondrial com aumento concomitante do potencial redox celular. $\mathrm{O}$ resultado é o aumento paralelo na produção intracelular de $\mathrm{EROs}^{54}$. Como a hipóxia diminui a oferta de $\mathrm{O}_{2}$ para o metabolismo celular, espera-se que a produção de EROs esteja menor nesta condição. Contudo, o que se nota é o oposto. A produção de EROs, principalmente de $\mathrm{O}_{2}{ }^{\bullet-}$ por mitocôndrias, é aumentada rapidamente com a elevação na altitude ${ }^{11}$. O mecanismo possivelmente responsável pela formação de EROs em condiçôes hipóxicas envolve o vazamento de elétrons nos complexos I e III do STE, principalmente se o STE se encontrar al tamente reduzido (MMI hiperpolarizada).

Isso significa que, embora o alto valor de potencial de MMI possa favorecer a síntese de ATP, em paralelo, também pode favorecer a maior produção de EROs, com a possibilidade de ocorrência de estresse oxidativo. Ou seja, pode-se dizer que o potencial de MMI elevado é o fator mais importante para a formação de EROs intramitocondrial, comparativamente ao consumo de $\mathrm{O}_{2}{ }^{55}$. Portanto, modificaçóes no potencial de MMI podem alterar o balanço existente entre produção de ATP e EROs; 
modificando, desta forma, o balanço existente entre esses parâmetros relacionados com metabolismo celular e bioenergética.

Outro problema que ressalta a importância do potencial de membrana e da hipóxia para a formação de EROs é a ocorrência de isquemia tecidual. Neste caso, a despolarização membranar é o mecanismo responsável pela sua produção e indução de estresse oxidativo. Os principais tecidos e órgãos investigados quanto aos efeitos da isquemia-reperfusão são, respectivamente, o tecido muscular esquelético e o miocárdio ${ }^{56}$.

No caso do músculo esquelético, uma contração com intensidade de $50 \%$ da força muscular voluntária máxima (MVC) pode induzir grande queda na oferta de nutrientes e $\mathrm{O}_{2}$ pela circulação sanguínea ${ }^{57}$. Foi demonstrado que mesmo a $10 \%$ da MVC já é possível reduzir a disponibilidade de $\mathrm{O}_{2}$ para a fibra muscular durante o exercício físico ${ }^{58}$. Portanto, durante a corrida o músculo esquelético passa por pequenos ciclos de contraçáo e relaxamento seguidos de isquemia e reperfusão.

No começo da isquemia cardíaca, o metabolismo anaeróbio é ativado rapidamente (8s) após a parada

\section{Bioeletricidade e apoptose}

O possível mecanismo envolvido com a produção de EROs em tecidos submetidos à isquemia-reperfusão relaciona-se com a ocorrência de vazamento de elétrons e $\mathrm{H}^{+}$através da MMI, resultando em despolarização membranar e queda na eficiência do $S T E^{61}$. A despolarização de MMI e EROs resultam na ativação de canais com permeabilidade transicional (mPTP). Com a sua abertura, a despolarização de MMI é exacerbada e as mitocôndrias passam a produzir mais EROs, um fenômeno denominado por "EROs induzindo liberaçấo de EROs" 52 .

Uma vez que mitocôndrias são organelas carregadas negativamente, a captação de $\mathrm{Ca}^{2+}$ é frequentemente associada com despolarização dessas organelas. Embora a concentração intracelular de $\mathrm{Ca}^{2+}$ aumente em situação de isquemia tecidual, a falta de energia devido à despolarização impóe limites à sua captação por mitocôndrias ${ }^{62}$. Com a captação de $\mathrm{Ca}^{2+}$ por mitocôndrias pelos poros mPTP, a despolarização de MMI torna-se crítica para a célula ${ }^{8}$. Além disso, a combinação de EROs e $\mathrm{Ca}^{2+}$ mitocondriais resulta na abertura desses canais de forma mais efetiva. Devido a essas propriedades, canais mPTP ativados representam um "ponto sem retorno" porque, após isso, o tecido muscular no fluxo de sangue, com a contração do miocárdio declinando em $20 \mathrm{~s}$. As propriedades elétricas teciduais mudam rapidamente: o potencial de ação celular encurta e o segmento ST do eletrocardiograma é elevado com um minuto de isquemia. $\mathrm{O}$ $\mathrm{pH}$ intracelular diminui e a glicólise anaeróbia é parcialmente inibida. Com o tempo, a isquemia promove aumento no $\mathrm{Na}^{+}$intracelular e o potencial de MMI declina progressivamente ${ }^{56}$.

A maior produção de EROs devido à isquemia tecidual pode ser atribuida à perda do potencial de MMI, que não se recupera com a reperfusão. Antioxidantes químicos atenuam esse efeito, assim como a ocorrência de peroxidação lídica e morte celular após reperfusão $0^{56}$. Esses estudos mostram que tanto a despolarização como a hiperpolarização da MMI são importantes fatores envolvidos com produção intramitocondrial de EROs, e por mecanismos distintos ${ }^{59}$. Esse fato justifica a afirmação anterior neste texto de que mitocôndrias funcionam melhor e com mais eficiência em estado redox e potencial de MMI intermediários ${ }^{60}$.

é irreversivelmente acometido de modificaçóes funcionais que culminam em apoptose ou necrose.

Canais mPTP são formados por complexos proteicos de VDAC (do inglês "voltage dependent anion channel"), ciclofilina D e $\mathrm{ANT}^{3}$. Essas e outras proteínas menos importantes formam um canal que possibilita o contato entre MMI e MME. Uma vez que VDAC é o único canal conhecido que possibilita o fluxo de metabólitos através da membrana MME, sua condutância pode controlar o metabolismo mitocondrial através da modulação do transporte de ATP para o citosol ${ }^{8}$.

Moléculas com baixo peso molecular $(1,5 \mathrm{kDa})$ podem adentrar as mitocôndrias através de $\mathrm{mPTP}$, causando aumento no seu volume e ruptura da MME. Como consequência, fatores intracelulares relacionados com mitofagia e apoptose são elevados. Em geral, considera-se que a despolarização mitocondrial é pré-requisito para autofagia, assim como a liberaçáo de moléculas de citocromo $\mathrm{C}$ para o citosol ${ }^{56}$. Através da mitofagia, mitocôndrias lesionadas ou com mal funcionamento são eliminadas ${ }^{62}$.

A apoptose é também considerada um componente vital de vários processos, incluindo, "turnover" de células normais, desenvolvimento e 
funcionamento apropriado de células imunitárias, desenvolvimento embrionário e indução química de morte celular. Por outro lado, apoptose inapropriada (muito ou pouco) é um fator importante em muitas condições incompatíveis com a vida como, doenças neurodegenerativas, danos teciduais por isquemia, desordens autoimunes e alguns tipos de câncer ${ }^{63}$.

A deficiência bioenergética resultante da despolarização mitocondrial resulta em ativação reversa da $\mathrm{F}_{1} \mathrm{~F}_{0}$ ATP sintase, fazendo com que as mitocôndrias tornem-se as principais consumidoras de ATP da célula. Ou seja, com a dissipação do gradiente de $\mathrm{H}^{+}$, a ATP sintase passa a se comportar como ATPase ${ }^{64}$. Nesta condição, o sistema ANT reverte seu estado funcional e passa a favorecer o consumo mitocondrial de ATP produzido pela glicólise. O déficit de ATP resultante acarreta em grande elevação na atividade da glicólise e maior produção de lactato. Em termos metabólicos, esse é um meio intracelular bastante favorável à produção de EROs por mecanismo localizado no citosol que, embora importante, não será descrito neste texto.

Estudos demonstraram que a via de sinalização para a apoptose, que pode ser ativada pelo exercício físico intenso, envolve as proteínas Bax e Bcl-2. Bax é uma proteína localizada principalmente no citoplasma celular, podendo migrar para o interior de mitocôndrias e combinar com ANT ou VDAC. A Bcl-2 é a principal proteína inibidora da apoptose, encontrando-se geralmente ancorada na mitocôndria, retículo endoplasmático e envelope nuclear no lado citoplasmático. Essa ação mantém a integridade da membrana mitocondrial através da competição com Bax e manutenção do canal mPTP fechado. O resultado é o melhor controle da sua abertura, inibição do fluxo transmembranar de $\mathrm{Ca}^{2+} \mathrm{e}$ consequente prevenção da apoptose.

Foi demonstrado em músculo esquelético de ratos que a expressão de Bax aumenta e a de Bcl diminui após o treinamento físico com exercícios físicos intensos. A queda significativa na razão $\mathrm{Bcl} / \mathrm{Bax}$ demonstra que o exercício físico intenso utilizado regularmente no TFE pode ativar processos intracelulares responsáveis pela apoptose. Além disso, foi sugerido que o mecanismo da sua indução pelo exercício físico com essas características pode resultar da abertura de canais mPTP devido à despolarização mitocondrial, EROs e deficiência bioenergética ${ }^{65}$.

Como salientado antes, mitocôndrias desempenham papel importante em problemas relacionados com isquemia e reperfusão tecidual. Embora existam mais estudos sobre o seu mecanismo no miocárdio devido aos problemas relacionados com transplantes desse órgão, estudos recentes utilizaram modelos de isquemia-reperfusão para avaliar o papel de mPTP com seus efeitos no músculo esquelético de ratos. Para tanto, um inibidor específico desse canal, NIM811, análogo da ciclosporina $A$, foi utilizado após três horas de isquemia e quatro de reperfusão em membros inferiores de ratos.

Esse estudo demonstrou que NIM-811 foi capaz de reduzir valores séricos de indicadores de lesôes teciduais (lactato desidrogenase e creatina quinase) no modelo experimental utilizado no estudo. Portanto, a inibição da abertura de canais mPTP exerce papel protetor do tecido muscular na condição de isquemia-reperfusão ${ }^{66}$. Desta forma, pode-se dizer que canais mPTP também exercem na musculatura esquelética papel parecido com o que acontece no miocárdio.

Adicionalmente, foi demonstrado em estudos com músculo gastrocnêmio de ratos submetidos a 14 semanas de exercícios físicos em esteira rolante específica para esses animais, elevação nas funçóes oxidativas mitocondriais e ativação de canais mPTP nesta condição. Neste mesmo estudo, a enzima caspase-9, indicadora de susceptibilidade para apoptose, apresentou atividade elevada ${ }^{67}$. Caspases são famílias de endoproteases que controlam a inflamação e morte celular. A caspase- 9 está diretamente relacionada com apoptose em mamíferos ${ }^{68}$.

\section{Papel do $\mathrm{Ca}^{2+}$ e EROs na proliferação mitocondrial}

Em função do que foi exposto até aqui, pode-se fazer a seguinte indagação: qual seria o mecanismo responsável pela tradução das características temporais da despolarização membranar induzida pelo exercício físico em sinalização intracelular apropriada para ativar ou inibir a transcrição de genes específicos? ${ }^{69}$ Esta questão envolve a importância de se saber como padrốes de despolarizaçóes são descodificados e traduzidos em mudanças no nível de fatores de transcrição e de outras proteínas reguladoras da expressão de genes em proteínas estruturais e funcionais ${ }^{70}$.

Sinais relacionados com mudanças em estímulos da contração muscular são consequência de padróes existentes na atividade elétrica desencadeada por alteraçôes na atividade de motoneurônios. Como 
modificaçôes nesta variável provocam alteraçóes na expressão gênica, considera-se que deve existir acoplamento entre excitação elétrica e transcrição.

Foi sugerido que mudanças desencadeadas no músculo pela atividade elétrica do nervo podem resultar em grande variedade de atividades correlacionadas com potencial para modificar a transcrição gênica. O exemplo mais notório, neste caso, é o aumento na concentraçáo intracelular de $\mathrm{Ca}^{2+}$ livre devido ao seu influxo através de membranas el ou liberaçōes do retículo endoplasmático. Outras modificações são: aumento na concentração de metabólitos, hipóxia e estresse mecânico ${ }^{71}$.

Cogita-se que mudanças na concentração plasmática de $\mathrm{Ca}^{2+}$ possam afetar as propriedades físicas da cromatina, com possibilidades de facilitação da transcrição, principalmente por expor regiōes do DNA a esse processo ${ }^{72}$. Portanto, modificaçóes nas propriedades iônicas do tecido muscular podem afetar tanto o DFE como processos relacionados com biossíntese ${ }^{72}$.

Essas modificaçôes inter-relacionadas podem ser detectadas por sensores, como no caso de proteínas quinases C ("PKC"), calmodulina, AMPK e PPAR- $\gamma$ ("peroxisome proliferator-activated receptor-gamma”), que desencadeiam cascatas de sinalizaçáo intracelular. PPAR- $\gamma$ é um membro da família de receptores nucleares de fatores de transcrição (grupo diverso de proteínas) que promovem ativaçáo ou repressão da transcrição. Entretanto, a atividade desses sensores depende de diversos fatores, como histórico celular (linhagem); características da atividade elétrica a que o nervo é submetido; condições mecânicas e; condiçóes parácrinas, autócrinas e endócrinas ${ }^{71}$.

Portanto, apesar de existir consenso de que mudanças na atividade muscular transformam suas características fenotípicas, não se sabe exatamente que mecanismo de sinalização biológica é responsável por essas mudanças ${ }^{73}$. Outro aspecto importante é a possibilidade de amplificação de sinais existentes entre vias de sinalização complexas, como no caso da ação de AMPc (AMP cíclico) $)^{74}$.

$\mathrm{O} \mathrm{Ca}^{2+}$ intracelular livre é o mais abundante e mais potente de todos os segundos mensageiros conhecidos, sendo que a atividade do potencial de ação membranar pode desencadear grande liberação de $\mathrm{Ca}^{2+}$ do retículo endoplasmático de qualquer célula, mesmo em condiçôes fisiológicas. Esta constatação fez com que flutuaçôes na concentração citosólica de $\mathrm{Ca}^{2+}$ fossem consideradas o principal candidato mediador dos efeitos da atividade elétrica no fenótipo muscular.

Existem muitas evidências de que o $\mathrm{Ca}^{2+}$ pode ser responsável pelas modificaçôes ocorridas no tecido muscular em longo prazo devido a sua capacidade de controlar a expressão gênica. Além disso, diferentes concentraçóes de $\mathrm{Ca}^{2+}$ podem gerar fluxos contendo diferentes frequências ou padrões interpretados como estímulos específicos por genes. Modificações no $\mathrm{Ca}^{2+}$ citoplasmático têm sido associadas com acumulo de $\mathrm{Ca}^{2+}$ nuclear e expressão gênica ${ }^{71}$. Por exemplo, a despolarização de músculos de contração rápida com estímulos tônicos com baixa frequência $(10 \mathrm{~Hz})$ induziu mudanças nas sequências da síntese de isoformas da miosina de cadeia pesada, assim como mudanças em processos intracelulares envolvendo a presença de $\mathrm{Ca}^{2+}$. Outros genes ativados por aumento no $\mathrm{Ca}^{2+}$ intracelular são o GLUT-4 e genes relacionados com biogênese mitocondrial ${ }^{75}$.

$\mathrm{O} \mathrm{Ca}^{2+}$ pode, nesta perspectiva, ser considerado o elo entre excitação elétrica e expressão gênica. Por exemplo, o $\mathrm{Ca}^{2+}$ regula processos básicos da célula como proliferação, síntese proteica e diferenciação, mas está também envolvido com funçôes mais conhecidas como a contração muscular, liberação de neurotransmissores, excitabilidade elétrica e plasticidade fenotípica. Fontes intracelulares $\mathrm{de}^{\mathrm{Ca}^{2+}}$ envolvidas com regulação da expressão gênica são os retículos endoplasmático e nucleoplásmico, $\mathrm{Ca}^{2+} \mathrm{de}$ mitocôndrias, grânulos de secreção do citoplasma e microvesículas nucleares ${ }^{75}$.

O sinal do $\mathrm{Ca}^{2+}$ no núcleo tem efeitos distintos na transcrição gênica e no desenvolvimento e crescimento celular, comparativamente ao sinal do $\mathrm{Ca}^{2+}$ citosólico. Entretanto, não é totalmente conhecido como o sinal do $\mathrm{Ca}^{2+}$ nuclear é regulado. Foi demonstrada a presença de uma formação reticular envolvendo os estoques de $\mathrm{Ca}^{2+}$ nuclear que é contínua com o retículo endoplasmático e o envelope nuclear. Estudos recentes relataram a presença de receptores de inositol 3 -fosfato (IP3) em membranas dessa rede ${ }^{76}$.

O primeiro nível que envolve a intervenção da sinalização do $\mathrm{Ca}^{2+}$ na regulação gênica compreende canais de membrana que detectam vários estímulos, como mudanças na voltagem, ligantes extracelulares e aumento na concentraçáo intracelular de $\mathrm{Ca}^{2+}$. Canais de $\mathrm{Ca}^{2+}$ disponíveis na membrana compreendem: 1) Canais sensíveis à voltagem; 2) Canais ativados por receptores (NMDA) e; 3) Canais presentes em locais de estoques de $\mathrm{Ca}^{2+}$. $\mathrm{O}$ terceiro tipo de canal é composto por aqueles que liberam $\mathrm{Ca}^{2+}$ sob a influência positiva, por exemplo, de sensores de voltagem (receptores de dihidropiridina), receptores de rianodina e IP3, que mobilizam $\mathrm{Ca}^{2+}$ do retículo endoplasmático. Canais de $\mathrm{Ca}^{2+}$ sensíveis à voltagem representam o principal modelo na compreensão de 
processos envolvendo acoplamento elétrico-transcripcional, porque transformam atividade elétrica em informação a partir da sinalização do $\mathrm{Ca}^{2+}$.

Durante a contração muscular ocorrem oscilaçôes na concentração intracelular de $\mathrm{Ca}^{2+}$, cuja amplitude e duraçáo são função do nível da força produzida pelo tecido muscular ${ }^{77}$. Modificaçóes no $\mathrm{Ca}^{2+}$ intracelular podem ser traduzidas em sinais discretos que modulam a atividade de CaMKs. CaMKs, assim como proteínas quinases $\mathrm{C}$ e calmodulinas, são sensores primários de modificaçóes no $\mathrm{Ca}^{2+}$ intracelular. A CaMK é ativada pelo complexo $\mathrm{Ca}^{2+}$-calmodulina. Além de descodificar o $\mathrm{Ca}^{2+}$ intracelular, a CaMK pode ser ativada de forma diferente dependendo do padrão de flutuação de sua concentração. Como a despolarização da MMI ativa a captação intramitocondrial de $\mathrm{Ca}^{2+}$ e produçáo de EROs, pode-se dizer que todos esses processos encontram-se relacionados com bioeletricidade celular ${ }^{73}$.

Fatores de crescimento, citocinas e estresse celular impactam a atividade de proteínas quinases ativadas por mitógenos (MAPKs). MAPKs regulam eventos transcripcionais por fosforilação de diversos substratos localizados no citoplasma e no núcleo, incluindo fatores de transcrição e coativadores; regulando, desta forma, uma grande variedade de processos fisiológicos como, diferenciação, hipertrofia, inflamação e expressão gênica. EROs ativam diretamente MAPKs e o fator de transcrição nuclear $\kappa \mathrm{B}(\mathrm{NF}-\kappa \mathrm{B})$, relacionando sinais de tradução e processos transcripcionais ${ }^{1}$. NF- $\kappa B$ é um fator induzível que regula vários processos fisiológicos, incluindo respostas inflamatórias e apoptose. Em humanos, foi demonstrado que o resveratrol reduz a apoptose e a inflamação através da ativação de SIRT1 e consequente supressão da atividade de NF- $\kappa \mathrm{B}^{78}$.

O papel de EROs como estimulantes da biogênese mitocondrial foi primeiro proposto por Davies et al. ${ }^{79}$ no começo da década de 80 . Esses pesquisadores demonstraram pela primeira vez que EROs são produzidas no músculo esquelético de animais após o exercício físico realizado até a exaustâo. Foi sugerido pelos autores que o aumento da quantidade de mitocôndrias no tecido muscular poderia ser uma reposta compensatória aos danos causados nessas organelas por EROs. Estudos subsequentes demonstraram que PGC- $1 \alpha$ e PGC- $1 \beta$ são grandemente estimulados por $\mathrm{H}_{2} \mathrm{O}_{2}$, resultando em aumento na expressão de enzimas antioxidantes:
Mn-SOD, catalase e glutationa peroxidase (GPX), assim como UCP2 e UCP3 ${ }^{2}$.

Por outro lado, foi demonstrado em outros estudos que o efeito positivo do TFE de resistência em aumentar a produção intracelular muscular de fatores relacionados com biogênese mitocondrial, como: PGC-1 $\alpha$, NRF-1, TFAM e citocromo C (marcador de conteúdo mitocondrial) é suprimido por altas doses de vitamina C $(500 \mathrm{mg} / \mathrm{kg})$ utilizadas em estudos com animais. Esse efeito foi também verificado para as enzimas antioxidantes $\mathrm{Mn}-\mathrm{SOD}$ e GPX. Portanto, apesar de EROs terem sido consideradas lesivas ao organismo nas décadas de 70 e 80, estudos recentes mostraram que EROs podem exercer papel importante no organismo como moléculas sinalizadoras envolvidas com biossíntese.

Em revisão recente sobre esse assunto, os autores colocaram em dúvida o papel do consumo de antioxidantes químicos, como no caso das vitaminas $\mathrm{C}$ e E em associação ao TFE de resistência, porque podem reduzir os efeitos sinalizadores de EROs relacionados com biossíntese induzida pelo exercício físico e TFE².

Em função disso, um novo conceito foi proposto que diz respeito à biogênese mitocondrial desencadeada por baixas doses de EROs como medida para contrabalancear o estresse sofrido pelas células nesta condiçãa. Esse conceito foi denominado por hormese mitocondrial (mitohormese). Portanto, diferentes concentraçóes de um mesmo agente, neste caso, EROs, podem exercer efeitos náo-lineares na resposta fisiológica e metabólica: em baixas doses o estresse é benéfico, mas, em valores elevados, pode ser lesivo ao organismo ${ }^{2}$.

O efeito hormético de EROs na biossíntese celular pode ser apreciado da seguinte forma: o aumento agudo de EROs no tecido muscular durante o exercício físico serve de estímulo para a produçáo celular de mitocôndrias. Contudo, sua produção de forma exacerbada promove supressão da biogênese e ativação da mitofagia ${ }^{11}$. Entretanto, como descrito antes, polifenóis são antioxidantes e estimulam o aumento do volume mitocondrial em tecidos do organismo, o que contraria parcialmente a mitohormese. Neste sentido, cabe ressaltar a possibilidade de que o mecanismo envolvido não seja o seu potencial antioxidante, mas, as suas capacidades de modificar a polaridade de cargas de membranas de células ou devido aos seus efeitos sobre a enzima SIRT1. 
Pereira B.

\title{
Considerações finais
}

Diversos fatores alterados no organismo pelo exercício físico podem estar envolvidos com biossíntese e duplicação de organelas. Neste ensaio, a hipótese proposta é a do acoplamento elétrico-transcripcional. O mecanismo sugerido para explica-la é a ocorrência de despolarização de cargas em células e organelas. A despolarizaçáo efetiva ocorre na fibra muscular em funçáo do impulso nervoso, principalmente pela elevação do $\mathrm{Ca}^{2+}$ intracelular e pela sua captação por mitocôndrias devido a abertura de canais mPTP, com participação de EROs. Entretanto, apesar de a despolarização membranar moderada ser benéfica à funcionalidade celular, porque serve de estímulo para biossínteses, quando em excesso e de forma sustentada, encontra-se positivamente relacionada com autofagia, apoptose, necrose e morte celular. Portanto, é possível que o primeiro efeito possa estar relacionado com modificaçóes orgânicas e celulares positivas da atividade física moderada. Por outro lado, o exercício intenso praticado excessivamente, como no caso da síndrome de "overtraining", hipóxia e efeitos da altitude elevada, com o segundo.

\begin{abstract}
Mitochondrial biogenesis and physical exercise: electric-transcriptional coupling hypothesis

One of the main changes happened in skeletal muscle tissue as a result of physical and sport training with prolonged exercise is the increase in the quantity and functional quality of mitochondria. There is not yet an explanatory causal mechanism for this phenomenon. The suggestion to be discussed in this assay is called "electric-transcriptional coupling hypothesis". In this hypothesis, changes in electrical activity, mainly membrane depolarization, are considered methods used for the control of biosynthesis in multicellular organisms. For example, studies that resulted in somatic cell hyperpolarization induced suppression of differentiation and proliferation, and the opposite happened with depolarization. That is, cell depolarization that occur during the exercise as a consequence of intense and prolonged muscle contraction could activate processes responsible for biosynthesis and, possibly, mitochondrial replication.
\end{abstract}

KEY WORDS: Bioenergetics; Bioelectricity; Endurance; Metabolism; Oxidative stress.

\section{Referências}

1. Hawley JA, Hargreaves M, Joyner MJ, Zierath JR. Integrative biology of exercise. Cell. 2014;159:738-49.

2. Gomez-Cabrera MC, Salvador-Pascual A, Cabo H, Ferrando B, Vina J. Redox modulation of mitochondriogenesis in exercise. Does antioxidant supplementation blunt the benefits of exercise training? Free Radic Biol Med. 2015;86:37-46.

3. Levin M. Molecular bioelectricity: how endogenous voltage potentials control cell behavior and instruct pattern regulation in vivo. Mol Biol Cell. 2014;25:3835-50.

4. Cohen AE, Venkatachalam V. Bringing bioelectricity to light. Annu Rev Biophys. 2014;43:211-32.

5. Friesen DE, Craddock TJ, Kalra AP, Tuszynski JA. Biological wires, communication systems, and implications for disease. Biosystems. 2015;127:14-27.

6. Levin M. Molecular bioelectricity in developmental biology: new tools and recent discoveries: control of cell behavior and pattern formation by transmembrane potential gradients. BioEssays. 2012;34:205-17.

7. Blackiston DJ, McLaughlin KA, Levin M. Bioelectric controls of cell proliferation: ion channels, membrane voltage and the cell cycle. Cell Cycle. 2009;8:3527-36.

8. O’Rourke B, Cortassa S, Aon MA. Mitochondrial ion channels: gatekeepers of life and death. Physiology (Bethesda). 2005;20:303-15.

9. Aon MA, Bhatt N, Cortassa SC. Mitochondrial and cellular mechanisms for managing lipid excess. Front Physiol. 2014;5:282. 
10. Kadenbach B, Ramzan R, Wen L, Vogt S. New extension of the Mitchell Theory for oxidative phosphorylation in mitochondria of living organisms. Biochim Biophys Acta. 2010;1800:205-12.

11. Murray AJ, Horscroft JA. Mitochondrial function at extreme high altitude. J Physiol. 2015. Epub 2015. doi: 10.1113/ JP270079.

12. Schiaffino S, Reggiani C. Fiber types in mammalian skeletal muscles. Physiol Rev. 2011;91:1447-531.

13. Safiulina D, Veksler V, Zharkovsky A, Kaasik A. Loss of mitochondrial membrane potential is associated with increase in mitochondrial volume: physiological role in neurones. J Cell Physiol. 2006;206:347-53.

14. Szent-Gyorgyi A. Bioelectronics and cancer. J Bioenerg. 1973;4:533-62.

15. Gonzalez MJ, Miranda Massari JR, Duconge J, et al. The bio-energetic theory of carcinogenesis. Medical hypotheses. 2012;79:433-9.

16. Levin M. Larg-scale biophysics: ion flow and regeneration. Trends in Cell Biol. 2007;17:261-70.

17. Henneman E, Somjen G, Carpenter DO. Excitability and inhibitability of motoneurons of different sizes. J Neurophysiol. 1965;28:599-620.

18. Duchateau J, Enoka RM. Human motor unit recordings: origins and insight into the integrated motor system. Brain Res. 2011;1409:42-61.

19. Wallinga-De Jonge W, Gielen FL, Wirtz P, De Jong P, Broenink J. The different intracellular action potentials of fast and slow muscle fibres. Electroencephalogr Clin Neurophysiol. 1985;60:539-47.

20. Heckman CJ, Enoka RM. Motor unit. Compr Physiol. 2012;2:2629-82.

21. Stauber T, Weinert S, Jentsch TJ. Cell biology and physiology of CLC chloride channels and transporters. Compr Physiol. 2012;2:1701-44.

22. van Wessel T, de Haan A, van der Laarse WJ, Jaspers RT. The muscle fiber type-fiber size paradox: hypertrophy or oxidative metabolism? Eur J Appl Physiol. 2010;110:665-94.

23. Noble D. Claude Bernard, the first systems biologist, and the future of physiology. Exper Physiol. 2008;93:16-26.

24. Noble D. Biophysics and systems biology. Philos Trans Series A, Math, Phys, and Eng Sci. 2010;368:1125-39.

25. Porter RK. Allometry of mammalian cellular oxygen consumption. Cell Mol Life Sci. 2001;58:815-22.

26. Larsen FJ, Schiffer TA, Sahlin K, Ekblom B, Weitzberg E, Lundberg JO. Mitochondrial oxygen affinity predicts basal metabolic rate in humans. Faseb J. 2011;25:2843-52.

27. Maughan RJ. Distance running in hot environments: a thermal challenge to the elite runner. Scand J Med Sci Sports. 2010;20 Suppl 3:95-102.

28. Schmitt S, Schulz S, Schropp EM, et al. Why to compare absolute numbers of mitochondria. Mitochondrion. 2014;19:113-23.

29. Pereira B. Teto metabólico como indicador de capacidade de tolerância ao esforço físico: importância da capacidade oxidativa de reserva. Rev Bras Educ Fis Esporte. 2014;28:683-89.

30. Koppenol WH, Bounds PL, Dang CV. Otto Warburg's contributions to current concepts of cancer metabolism. Nat Rev Cancer. 2011;11:325-37.

31. Folmes CD, Nelson TJ, Dzeja PP, Terzic A. Energy metabolism plasticity enables stemness programs. Ann NY Acad Sci. 2012;1254:82-9.

32. Schlagowski AI, Singh F, Charles AL, et al. Mitochondrial uncoupling reduces exercise capacity despite several skeletal muscle metabolic adaptations. J Appl Physiol (1985). 2014;116:364-75.

33. Sack MN. Mitochondrial depolarization and the role of uncoupling proteins in ischemia tolerance. Cardiovasc Res. 2006;72:210-9.

34. Aguer C, Fiehn O, Seifert EL, et al. Muscle uncoupling protein 3 overexpression mimics endurance training and reduces circulating biomarkers of incomplete beta-oxidation. FASEB J. 2013;27:4213-25.

35. Michel S, Wanet A, De Pauw A, Rommelaere G, Arnould T, Renard P. Crosstalk between mitochondrial (dys)function and mitochondrial abundance. J Cell Physiol. 2012;227:2297-310.

36. Moyes CD, Hood DA. Origins and consequences of mitochondrial variation in vertebrate muscle. Annu Rev Physiol. 2003;65:177-201.

37. Hulbert AJ, Pamplona R, Buffenstein R, Buttemer WA. Life and death: metabolic rate, membrane composition, and life span of animals. Physiol Rev. 2007;87:1175-213.

38. Holloszy JO, Fontana L. Caloric restriction in humans. Exp Gerontol. 2007;42:709-12.

39. Krustrup P, Ferguson RA, Kjaer M, Bangsbo J. ATP and heat production in human skeletal muscle during dynamic exercise: higher efficiency of anaerobic than aerobic ATP resynthesis. J Physiol. 2003;549:255-69. 
40. Constable SH, Favier RJ, McLane JA, Fell RD, Chen M, Holloszy JO. Energy metabolism in contracting rat skeletal muscle: adaptation to exercise training. Am J Physiol. 1987;253:C316-22.

41. Agutter PS. Cell mechanics and stress: from molecular details to the 'universal cell reaction' and hormesis. Bioessays. 2007;29:324-33.

42. Nogueiras R, Habegger KM, Chaudhary N, et al. Sirtuin 1 and sirtuin 3: physiological modulators of metabolism. Physiol Rev. 2012;92:1479-514.

43. Hoppeler H, Fluck M. Normal mammalian skeletal muscle and its phenotypic plasticity. J Exp Biol. 2002;205:2143-52.

44. Hoppeler H, Baum O, Lurman G, Moeller M. Molecular mechanism of muscle plasticity with exercise. Compr Physiol. 2011;1:1383-412.

45. Canto C, Jiang LQ, Deshmukh AS, et al. Interdependence of AMPK and SIRT1 for metabolic adaptation to fasting and exercise in skeletal muscle. Cell Metab. 2010;11:213-9.

46. Kulkarni SS, Canto C. The molecular targets of resveratrol. Biochim Biophys Acta. 2015;1852:1114-23.

47. Sandoval-Acuna C, Ferreira J, Speisky H. Polyphenols and mitochondria: an update on their increasingly emerging ROS-scavenging independent actions. Arch Biochem Biophys. 2014;559:75-90.

48. Vila-Cha C, Falla D, Farina D. Motor unit behavior duri endurance or strength training. J Appl Physiol (1985). 2010;109:1455-66.

49. Gardiner P, Dai Y, Heckman CJ. Effects of exercise training on alpha-motoneurons. J Appl Physiol (1985). 2006;101:1228-36.

50. Buonanno A, Fields RD. Gene regulation by patterned electrical activity during neural and skeletal muscle development. Curr Opin Neurobiol. 1999;9:110-20.

51. Piersma T. Why marathon migrants get away with high metabolic ceilings: towards an ecology of physiological restraint. The J Exper Biol. 2011;214:295-302.

52. Zorov DB, Juhaszova M, Sollott SJ. Mitochondrial reactive oxygen species (ROS) and ROS-induced ROS release. Physiol Rev. 2014;94:909-50.

53. Barja G. Mitochondrial oxygen consumption and reactive oxygen species production are independently modulated: implications for aging studies. Rejuv Res. 2007;10:215-24.

54. Solaini G, Baracca A, Lenaz G, Sgarbi G. Hypoxia and mitochondrial oxidative metabolism. Biochim Biophys Acta. 2010;1797:1171-7.

55. Van Voorhies WA. Live fast--live long? A commentary on a recent paper by Speakman et al. Aging cell. 2004;3:327-30.

56. Levraut J, Iwase H, Shao ZH, Vanden Hoek TL, Schumacker PT. Cell death during ischemia: relationship to mitochondrial depolarization and ROS generation. Am J Physiol Heart Circ Physiol. 2003;284:H549-58.

57. Sadamoto T, Bonde-Petersen F, Suzuki Y. Skeletal muscle tension, flow, pressure, and EMG during sustained isometric contractions in humans. Eur J Appl Physiol Occup Physiol. 1983;51:395-408.

58. Murthy G, Hargens AR, Lehman S, Rempel DM. Ischemia causes muscle fatigue. J Orthop Res. 2001;19:436-40.

59. Bernardi P, Petronilli V, Di Lisa F, Forte M. A mitochondrial perspective on cell death. Trends Biochem Sci. 2001;26:112-7.

60. Cortassa S, O’Rourke B, Aon MA. Redox-optimized ROS balance and the relationship between mitochondrial respiration and ROS. Biochim Biophys Acta. 2014;1837:287-95.

61. Yang KC, Bonini MG, Dudley SC, Jr. Mitochondria and arrhythmias. Free Radic Biol Med. 2014;71:351-61.

62. Duchen MR. Mitochondria and $\mathrm{Ca}\left(2^{+}\right)$in cell physiology and pathophysiology. Cell Calcium. 2000;28:339-48.

63. Elmore S. Apoptosis: a review of programmed cell death. Toxicol Pathol. 2007;35:495-516.

64. Chinopoulos C, Adam-Vizi V. Mitochondria as ATP consumers in cellular pathology. Biochim Biophys Acta. 2010;1802:221-7.

65. Liu WY, He W, Li H. Exhaustive training increases uncoupling protein 2 expression and decreases Bcl-2/Bax ratio in rat skeletal muscle. Oxid Med Cell Longev. 2013;2013:780719.

66. Garbaisz D, Turoczi Z, Aranyi P, et al. Attenuation of skeletal muscle and renal injury to the lower limb following ischemia-reperfusion using mPTP inhibitor NIM-811. PLoS One. 2014;9:e101067.

67. Lumini-Oliveira J, Magalhaes J, Pereira CV, Aleixo I, Oliveira PJ, Ascensao A. Endurance training improves gastrocnemius mitochondrial function despite increased susceptibility to permeability transition. Mitochondrion. 2009;9:454-62.

68. Crawford ED, Wells JA. Caspase substrates and cellular remodeling. Annu Rev Biochem. 2011;80:1055-87.

69. Hughes SM. Muscle development: electrical control of gene expression. Curr Biol. 1998;8:R892-4.

70. Fields RD, Lee PR, Cohen JE. Temporal integration of intracellular Ca2 ${ }^{+}$signaling networks in regulating gene expression by action potentials. Cell Calcium. 2005;37:433-42. 
71. Gundersen K. Excitation-transcription coupling in skeletal muscle: the molecular pathways of exercise. Biol Rev Camb Philos Soc. 2011;86:564-600.

72. De Loof A, De Haes W, Boerjan B, Schoofs L. The Fading Electricity Theory of Ageing: The missing biophysical principle? Ageing Res Rev. 2013;12:58-66.

73. Egan B, Zierath JR. Exercise metabolism and the molecular regulation of skeletal muscle adaptation. Cell Metab. 2013;17:162-84.

74. Berdeaux R, Stewart R. cAMP signaling in skeletal muscle adaptation: hypertrophy, metabolism, and regeneration. Am J Physiol Endocrinol Metab. 2012;303:E1-17.

75. Barbado M, Fablet K, Ronjat M, De Waard M. Gene regulation by voltage-dependent calcium channels. Biochim Biophys Acta. 2009;1793:1096-104.

76. Oliveira AG, Guimaraes ES, Andrade LM, Menezes GB, Fatima Leite M. Decoding calcium signaling across the nucleus. Physiology (Bethesda). 2014;29:361-8.

77. Allen DG, Lamb GD, Westerblad H. Skeletal muscle fatigue: cellular mechanisms. Physiol Rev. 2008;88:287-332.

78. Eo SH, Cho H, Kim SJ. Resveratrol inhibits nitric oxide-induced apoptosis via the NF-Kappa B pathway in rabbit articular chondrocytes. Biomol Ther (Seoul). 2013;21:364-70.

79. Davies KJ, Quintanilha AT, Brooks GA, Packer L. Free radicals and tissue damage produced by exercise. Biochem Biophys Res Comm. 1982;107:1198-205.

\begin{tabular}{|c|c|}
\hline $\begin{array}{r}\text { ENDEREÇO } \\
\text { Benedito Pereira } \\
\text { Departamento de Esporte } \\
\text { Escola de Educação Física e Esporte - USP } \\
\text { Av. Prof. Mello Moraes, } 65 \\
\text { 05508-030 - São Paulo - SP - BRASIL } \\
\text { e-mail: benepe@usp.br }\end{array}$ & $\begin{array}{l}\text { Recebido para publicação: 11/ 09/ } 2015 \\
\text { Aceito: 05/ 10/2015 }\end{array}$ \\
\hline
\end{tabular}

